\title{
SUSTAINABLE CELLULOSE NANOCRYSTAL REINFORCED CHITOSAN/HPMC BIO-NANOCOMPOSITE FILMS CONTAINING MENTHOL OIL AS PACKAGING MATERIALS
}

\author{
SALAH A. A. MOHAMED, ${ }^{*}$ AHMED SALAMA, ${ }^{* *}$ MOHAMED EL-SAKHAWY ${ }^{* *}$ and \\ ABDELMAGEED M. OTHMAN*** \\ *Packaging Materials Department, National Research Centre, 33 El-Bohouth Str., \\ Dokki, P.O. 12622, Giza, Egypt \\ ** Cellulose and Paper Department, National Research Centre, 33 El-Bohouth Str., \\ Dokki, P.O. 12622, Giza, Egypt \\ ${ }^{* * * *}$ Microbial Chemistry Department, National Research Centre, 33 El Bohouth Str. \\ [former El Tahrir Str.], Dokki Giza, P.O. 12622, Egypt \\ $\bowtie$ Corresponding author: Salah A. A. Mohamed, salahazhar1@yahoo.com
}

Received November 17, 2020

There is a growing demand to develop biodegradable composite films, with enhanced water resistance, antimicrobial activity, high mechanical properties and low oxygen permeability. In the present study, chitosan/hydroxypropyl methylcellulose (HPMC) films reinforced with cellulose nanocrystal (CNC) and containing menthol oil were prepared for food packaging applications. Menthol oil was selected due to its antibacterial properties, as well as relatively low cost and wide availability. CNC was prepared from bagasse via acid degradation. The bio-composites were prepared through a simple and versatile solution mixing and casting method. The morphology, chemical composition, water absorption, mechanical properties and antibacterial activity of the films were investigated. FTIR spectra were used to evaluate the film structure in terms of the interactions between components. Data showed that the addition of CNC improved the mechanical properties of the formed films and the menthol oil enhanced their antibacterial properties. HPMC and HPMC/CNC reduced the water absorption of the pure chitosan membrane from $70 \%$ to $22 \%$ and $9-11 \%$ by weight, respectively, which makes these constituents a good alternative for producing packaging.

Keywords: chitosan-hydroxypropyl methylcellulose, cellulose nanocrystals CNC, menthol oil, bio-nanocomposite films, water absorption

\section{INTRODUCTION}

Foodborne pathogens, the main factor in deteriorating food quality, motivate the packaging community researchers to seek new strategies to inhibit microbial growth in foods. The packaging of fresh fruits and vegetables is important for maintaining the quality and extending the shelf life of fresh products. ${ }^{1-3}$ Using antimicrobial films has been recently reported as an efficient tool for protecting fresh products and achieving a prolonged shelf life. Antimicrobial films can effectively inhibit food-spoiling microorganisms and foodborne pathogens. Such films are normally prepared by blending antimicrobial agents, immobilized or coated on the surface of the films. Although many antimicrobial films have been studied, their large-scale production is still limited. $^{4,5}$

The selection of packaging components needs to be done carefully, considering a possible direct effect of the inherent physicochemical properties of the film on food. Therefore, using green label and environmentally safe components has become an increasing trend in the field of green packaging materials. Rather than using synthetic polymers, natural renewable polymers (chitosan, cellulose, and protein etc.) are preferred in tailoring green packaging for food. Combining biodegradable packaging materials with antimicrobial agents offers benefits to the packaging system in terms of shelf life, food safety, and environmental protection. 
Polysaccharides, in particular, cellulose and its derivatives, as well as chitosan, are important renewable resources. These polymers are cheap and can be functionalized using simple processes. The biodegradability of these polysaccharides is an important feature, recommending them for application in different research fields. ${ }^{6}$ Cellulose, the most abundantly available biopolymer derived from plants and trees, has a highly crystalline ordered fraction alternating with amorphous disordered regions. ${ }^{7}$ Cellulosic nanomaterials could be isolated from different lignocellulosic sources, such as wood and agricultural residues, by various methods, such as chemical, mechanical or enzymatic treatments. ${ }^{8,9}$ Acid hydrolysis is mostly used to extract cellulose nanocrystals (CNCs). During acid hydrolysis using hydrochloric acid, sulfuric acid, or phosphoric acid, the amorphous fraction is cleaved, leaving distinct crystalline rods. ${ }^{10}$

Chitosan is the deacetylated form of chitin (a natural linear polysaccharide found in marine invertebrates and some insects). ${ }^{11}$ Usually, commercial chitosan has a 70-95\% degree of deacetylation, and its properties are often dependent on the residual N-acetyl-Dglucosamine groups. ${ }^{12}$ Chitosan and several of its innumerable derivatives can form thin membranous films to be used in packaging, ${ }^{13}$ encapsulation and drug delivery systems. ${ }^{14,15}$ Recently, several publications have emerged on blending chitosan with different polymers, such as poly(vinyl alcohol) ${ }^{16,17}$ poly(N-vinyl pyrrolidone), ${ }^{18}$ starch, ${ }^{19}$ cellulose and its derivatives etc. ${ }^{20}$

The hydroxypropyl methylcellulose (HPMC) molecule has several hydroxyl groups to form intermolecular hydrogen bonds, which compose the cellulose chains in the form of fibrils or bundles. HPMC is a potential material for different applications in various industries, such as textiles, drugs, paper and food. Due to its viscosity-enhancing and water-holding properties, it is often used in the food industries. ${ }^{21,22}$ HPMC/polyethylene glycol composites have been developed as edible polymer films utilized directly in foodstuffs and for food packing. ${ }^{23}$

Blending chitosan with natural polymers, such as HPMC, starch, pectin, gelatin and collagen, or with synthetic polymers, such as poly(vinyl alcohol), poly(vinyl pyrrolidone), has been suggested as a promising approach to manufacturing polymers for specific uses. ${ }^{24-26}$
In the present work, polymer blends from chitosan/hydroxypropyl methylcellulose have been prepared using different ratios of chitosan/hydroxypropyl methylcellulose, CNC and menthol. The prepared films are insoluble in water and have a certain degree of swellability, but they are completely natural materials, without any synthetic residues. Thus, this kind of films will be suitable for packaging solid products. Moreover, these films could be adjusted to reach specific properties. The effect of HPMC and $\mathrm{HPMC} / \mathrm{CNC}$ in enhancing the water absorption of the pure chitosan membrane was assessed and the blended films were characterized by FTIR and SEM. Their antibacterial activity was also evaluated.

\section{EXPERIMENTAL \\ Materials}

Microcrystalline chitosan was supplied by Acros (molecular weight from 100.000 to 300.000 , and degree of deacetylation from 70 to $85 \%$ ). Hydroxypropyl methylcellulose, supplied by SigmaAldrich, exhibited the following specifications: viscosity ( $2 \mathrm{wt} \%$ in $\mathrm{H}_{2} \mathrm{O}$ ) $5 \mathrm{cps}, 0.1-0.3 \mathrm{~mol}$ propylene oxide per mol cellulose (MS), degree of substitution (DS) 1.1-1.6 mol methoxy per mole cellulose and average $M_{n} \sim 90000$. Bleached kraft bagasse pulp was kindly provided by Qena Company for Pulp and Paper, Egypt. The chemical composition of the bagasse pulp was the following: ash $0.82 \%$, pentosans $26.8 \%, \alpha-$ cellulose $70.6 \%$, and degree of polymerization (number of units of glucose in cellulose chain) 1174. Menthol was supplied by the National Research Center, and Tween 80 was supplied by Merck.

\section{Preparation of cellulose nanocrystals (CNCs) from bagasse pulp}

Cellulose nanocrystals were prepared from alphacellulose isolated from bagasse pulp, using sulfuric acid hydrolysis, according to the method described previously. Briefly, $20 \mathrm{~g}$ of dry bagasse pulp was added to $200 \mathrm{~mL}$ of sulfuric acid (64 wt\%) preheated to $45{ }^{\circ} \mathrm{C}$. The reaction was kept at $45{ }^{\circ} \mathrm{C}$ for $25 \mathrm{~min}$, followed by a dilution to $10 \%$ of the original concentration to end the reaction. The suspension was centrifuged at $6000 \mathrm{rpm}$ for $15 \mathrm{~min}$, washed with water and centrifuged again. The remaining acid was washed for some days until the neutrality of the wash water was achieved. The resulting cellulose nanocrystals suspension was sonicated for $15 \mathrm{~min}$, using an Ultrasonic processor (Sonisc Vibracell, VCX 750, Sonic Materials, U.S.A.), equipped with a $3 \mathrm{~mm}$ tip at $60 \%$ of its maximum power. The suspension was then centrifuged at $7000 \mathrm{rpm}$ for $20 \mathrm{~min}$ to purify CNCs. The concentration determined by gravimetric analysis was $1.3 \mathrm{wt} \%$. The surface charge determined by 
conductometric titration was $0.6 \mathrm{mmol} / \mathrm{g}$. The solvent exchange technique of $\mathrm{CNCs}$ in an aqueous suspension from water to acetone, and then to chloroform, by centrifuging and re-dispersing steps, was carried out for removing the water. ${ }^{27}$

Preparation of blended chitosan/hydroxypropyl methylcellulose-based bio-composite films

A chitosan solution was prepared by dissolving $2 \mathrm{~g}$ of solid chitosan in $1 \%$ acetic acid solution under stirring, overnight, at $60{ }^{\circ} \mathrm{C}$, and then filtered. $2 \%$ hydroxypropyl methylcellulose was prepared by dissolving $2 \mathrm{~g}$ of the material in distilled water. The two polymers were mixed thoroughly by stirring. The film was prepared by casting the polymers in polyethylene Petri dishes at a constant ratio of glycerol $(30 \%)$, and left to dry at room temperature. The other films were prepared by the same technique after adding adequate amounts of cellulose nanocrystals, Tween and menthol oil during the stirring process according to the composition presented in Table 1 and Table 2. The role of menthol oil was to enhance the antibacterial properties of the films, and Tween was used as surfactant to suspend the menthol oil in the aqueous solution.

\section{Characterization}

Transmission electron microscopy (TEM)

Transmission electron microscopy (TEM) images for CNCs were taken with a JEOL JEM-2100 electron microscope, at $100 \mathrm{k} \times$ magnification, with an acceleration voltage of $120 \mathrm{kV}$.

\section{FT-IR spectroscopy}

Fourier transform infrared spectroscopy (FT-IR) was performed on the CNCs by a Mattson 5000 FTIR spectrometer, using $\mathrm{KBr}$ discs, in the range of 4000$500 \mathrm{~cm}^{-1}$.

\section{Mechanical testing}

Tensile tests on the nanocomposites were carried out using a Lloyd instrument, West Sussex, UK, at room temperature. The distance between the jaws was $10 \mathrm{~mm}$, the crosshead speed was $0.6 \mathrm{~mm} \mathrm{~min}^{-1}$ for the first $250 \mathrm{~s}$, after that $1.5 \mathrm{~mm} \mathrm{~min}^{-1}$ up to $2000 \mathrm{~s}$, and finally $3 \mathrm{~mm} \mathrm{~min}^{-1}$ up to the break. The sample dimensions were $20 \times 5 \mathrm{~mm}$. Thickness was measured with a hand-held digimatic micrometer (QuantuMike Mitutoyo). Four thickness measurements in different spots were taken for every sample, the results being in the range from 0.15 to $0.2 \mathrm{~mm}$. The mechanical properties of the composite films (basis weight, thickness, tensile strength and burst strength) were determined according to standards ISO 536, ISO 534, ISO 1924-3 and ISO 1974, respectively. Five replicate measurements were performed for each sample and the average was calculated.
Effect of hydroxypropyl methylcellulose and cellulose nanocrystals with chitosan on water absorption

Water absorption was established by weighing different chitosan/hydroxypropyl methylcellulose films reinforced with cellulose nanocrystals (CNCs) before and after soaking in water (Table 3). The specimens were placed in a container with distilled water at a temperature of $23 \pm 1{ }^{\circ} \mathrm{C}$ and remained entirely immersed for two hours. After $2 \mathrm{~h}$, the specimens were removed from the water, were wiped off with a dry cloth and immediately weighed to the nearest $0.001 \mathrm{~g}$. The increase in weight (swelling), $\%$, was calculated as follows:

Increase in weight (Swelling), \% $=\frac{\left(\mathrm{W}_{\mathrm{t}}-\mathrm{W}_{\mathbf{0}}\right)}{\mathrm{W}_{\mathbf{0}}} \times 100$

where $\mathrm{W}_{0}$ is the initial dry mass and $\mathrm{W}_{\mathrm{t}}$ is the swollen mass at time $t$, respectively.

\section{Air permeability measurements}

Air permeability is a critical property of films to be used in food packaging. The air permeability values of the films were measured using a Bendtsen smoothness and porosity tester made in Denmark, Andersson Sorensen, Copenhagen.

\section{Scanning electron microscopy (SEM)}

FE-SEM scanning electron microscopy (FEI Quanta 200 scanning electron microscope, FEI Company BV, Netherlands, with an acceleration voltage of $20 \mathrm{kV}$ ) was used to investigate the surface morphology of the samples.

\section{Antimicrobial evaluation \\ Microorganisms}

Escherichia coli, Bacillus mycoides and Candida albicans were selected to represent various microbial populations, i.e. Gram-negative and Gram-positive bacterial strains, and a non-filamentous fungal strain, respectively, in order to estimate the antimicrobial potency of the chitosan treated films. The microbial strains were grown at $37{ }^{\circ} \mathrm{C}$ on a nutrient agar medium, then kept at $4{ }^{\circ} \mathrm{C}$ in agar slants at the Microbial Chemistry Department, National Research Centre, Dokki, Cairo, Egypt.

\section{Media}

E. coli, B. mycoides and C. albicans were cultured and sustained on slants of modified nutrient agar medium $(\mathrm{g} / \mathrm{L})$ : yeast extract, 1.5 ; peptone, 3; glucose, 0.5 ; meat extract, $1.5 ; \mathrm{NaCl}, 0.25$ and agar, 20.0 at $\mathrm{pH}$ 7.0. The same medium was used for antimicrobial assessment using the agar diffusion method, whereas, in the case of the shake flask method, nutrient broth medium with the same components described above, but without agar was used. The previously stated media were sterilized in an autoclave under 1.5 atmospheres for $20 \mathrm{~min}$ at $121{ }^{\circ} \mathrm{C}$. All the chemicals used were of analytical grade and of high purity. 
SALAH A. A. MOHAMED et al.

Assessment of antibacterial activity of the chitosan films by the agar diffusion method

To determine the effectiveness of the antimicrobial treatment of the chitosan films, the selected cultures were used for the antimicrobial activity test by inoculation of the nutrient agar medium (before solidification) with $100 \mu \mathrm{L}$ of the re-suspended overnight culture $\left(1 \times 10^{7} \mathrm{CFU} / 100 \mu \mathrm{L}\right)$ at $37{ }^{\circ} \mathrm{C}$. The nutrient agar medium was then poured into Petri dishes, where it solidified. Then, the chitosan film discs $(12 \mathrm{~mm})$ were fixed on the surface of the solidified agar plates, incubated overnight at $4{ }^{\circ} \mathrm{C}$, and then for $7 \mathrm{~h}$ at $37{ }^{\circ} \mathrm{C}$. The attained inhibition zones were calculated. $^{24,28,29}$

\section{Assessment of antimicrobial activity using dynamic contact conditions}

This test aimed to determine the antimicrobial activity of the treated chitosan films via shaking the samples in a bacterial culture suspension for a definite contact time. Erlenmeyer conical flasks $(250 \mathrm{~mL})$, having $50 \mathrm{~mL}$ of nutrient broth medium and equal samples of chitosan films ( $0.2 \mathrm{~g})$, were inoculated with $1 \mathrm{~mL}$ of the culture suspension containing $20 \times 10^{6}$ $\mathrm{CFU}$ and then incubated at $37{ }^{\circ} \mathrm{C}$, under stirring at 120 rpm for $2 \mathrm{~h}$. A reduction in the cell count for the tested cultures was assessed by determining the culture suspension turbidity before and after different treatments. The absorbance (turbidity) of different culture suspensions was determined at $660 \mathrm{~nm}$ and the percent of the reduction in colony-forming units ( $\mathrm{CFU})$ was calculated based on the following equation:
\% CFU Reduction $=(A-B) / A \times 100$

where $A$ is the average absorbance value of the tested microorganism for the control samples, and $B$ is the average absorbance after cultivation with the treated samples under shaking conditions. ${ }^{30}$

\section{RESULTS AND DISCUSSION}

The composite films were prepared from chitosan and hydroxypropyl methylcellulose after adding Tween as surfactant, glycerol as plasticizer, and $\mathrm{CNC}$ as reinforcing polymer, with/without menthol oil as bioactive agent, as shown in Tables 1 and 2.

\section{Morphology analysis TEM of cellulose nanocrystals}

It has been reported that controlled acid hydrolysis can split the amorphous regions in cellulose fibers and thus, decrease their size from micro- to nanoscale. ${ }^{31}$ The interior structure of the achieved CNCs extracted from bagasse pulp via acid hydrolysis was examined by TEM, as shown in Figure 1. It may be noted that CNCs appear as a rod-like structure, without any agglomerations. The isolated nanocrystals have a width of 5-7 nm, with the length in the range of 79-150 $\mathrm{nm}$. These results agree with those reported in other studies. ${ }^{32,33}$

Table 1

Chemical composition of the prepared samples (without menthol oil)

\begin{tabular}{|c|c|c|c|}
\hline \multirow[b]{2}{*}{$\begin{array}{c}\text { Sample } \\
\text { No. }\end{array}$} & \multicolumn{3}{|c|}{ Reactants } \\
\hline & $\begin{array}{c}\text { Chitosan, } \\
\mathrm{g}\end{array}$ & $\begin{array}{c}\text { HPMC, } \\
\mathrm{g}\end{array}$ & $\begin{array}{c}\text { Nanocellulose, } \\
\%\end{array}$ \\
\hline 1 & 60 & --- & --- \\
\hline 2 & --- & 60 & --- \\
\hline 3 & 30 & 30 & --- \\
\hline 4 & 30 & 30 & 1 \\
\hline 5 & 30 & 30 & 2 \\
\hline 6 & 30 & 30 & 3 \\
\hline 7 & 30 & 30 & 4 \\
\hline
\end{tabular}

Table 2

Chemical composition of the prepared films (with menthol oil)

\begin{tabular}{cccccc}
\hline \multirow{2}{*}{$\begin{array}{c}\text { Sample } \\
\text { No. }\end{array}$} & $\begin{array}{c}\text { Chitosan, } \\
\mathrm{g}\end{array}$ & $\begin{array}{c}\text { HPMC, } \\
\mathrm{g}\end{array}$ & $\begin{array}{c}\text { Nanocellulose, } \\
\%\end{array}$ & $\begin{array}{c}\text { Oil, } \\
\mathrm{mL}\end{array}$ & $\begin{array}{c}\text { Tween, } \\
\mathrm{mL}\end{array}$ \\
\hline 8 & 30 & 30 & --- & 0.25 & 0.25 \\
9 & 30 & 30 & --- & 0.5 & 0.5 \\
10 & 30 & 30 & 4 & 0.35 & 0.35 \\
11 & 30 & 30 & 4 & 0.4 & 0.4 \\
12 & 30 & 30 & 4 & 0.6 & 0.6 \\
13 & 30 & 30 & 4 & 0.8 & 0.8 \\
\hline
\end{tabular}




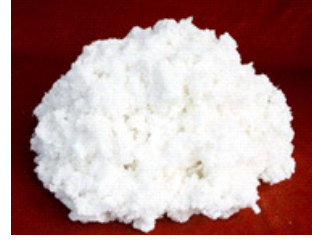

Bleached Bagasse Pulp

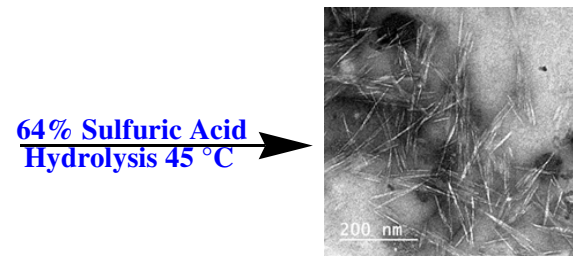

Cellulose nanocrystals

Figure 1: TEM image of CNCs extracted from bagasse pulp
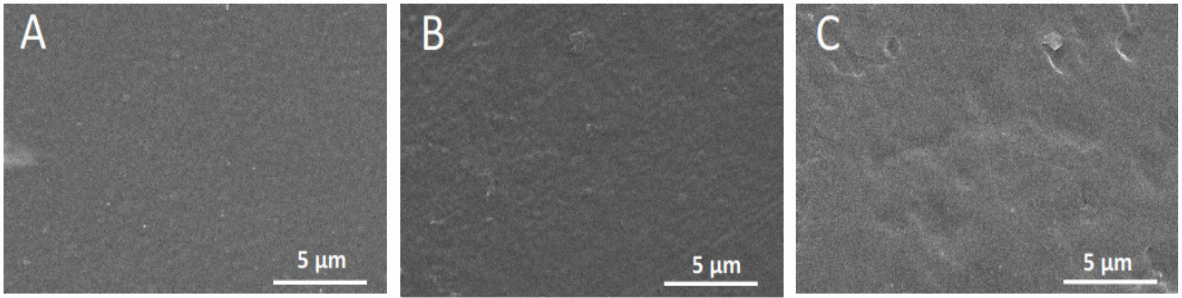

Figure 2: SEM micrographs of chitosan/hydroxypropyl methylcellulose film (A), chitosan/hydroxypropyl methylcellulose film with CNCs (B) and with menthol oil (C)

\section{SEM surface morphology analysis}

The surface morphology of the chitosan/hydroxypropyl methylcellulose films was evaluated by SEM, before and after their modification with CNCs and oil, and the micrographs are presented in Figure 2. The initial chitosan/hydroxypropyl methylcellulose film appears to be homogenous, likely due to the predictable hydrogen bonds produced between the two polymers. However, after adding $\mathrm{CNCs}$, the surface of the film becomes slightly rough, with clear evidence for uniform distribution of the $\mathrm{CNCs}$ in the films. Furthermore, after modification with menthol oil, the film surface was significantly transformed to a very smooth morphology. This proves the role of menthol oil in improving the interactions and miscibility between the components of the film.

\section{FT-IR spectroscopy}

Chitosan (Fig. 3 A) shows characteristic bands at $3450 \mathrm{~cm}^{-1}$, which are attributed to $\mathrm{NH}, \mathrm{OH}$ symmetric stretching vibration. The weak band at $2921 \mathrm{~cm}^{-1}$ is attributed to the $\mathrm{CH}$ stretch vibrations and the peaks at 1656 and $1580 \mathrm{~cm}^{-1}$ are due to the $\mathrm{C}=\mathrm{O}$ stretching (amide $\mathrm{I}$ ) and $-\mathrm{NH}$ stretching (amide II), respectively.
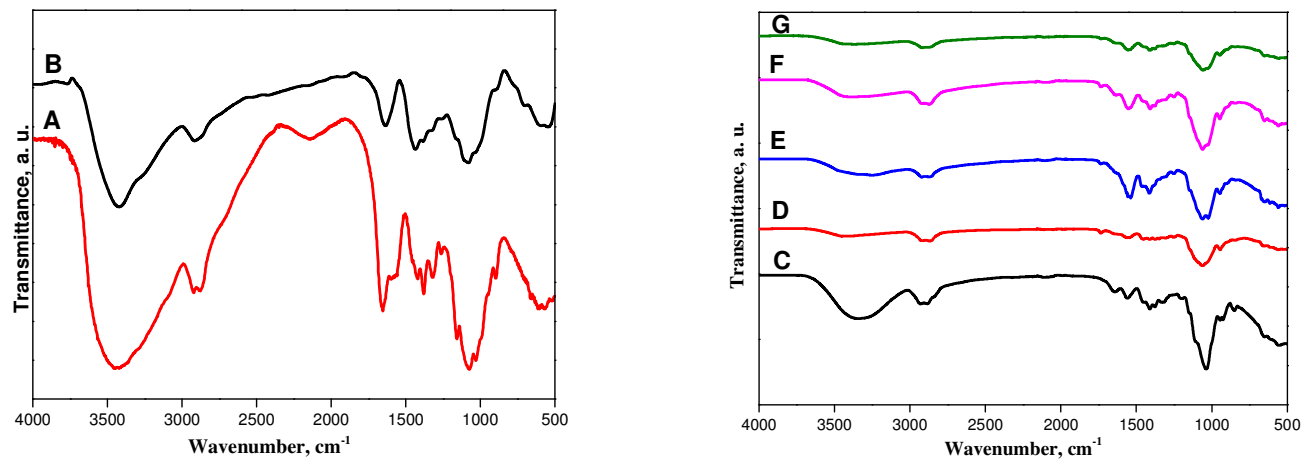

Figure 3: FT-IR spectra of chitosan (A), CNCs (B), chitosan/hydroxypropyl methylcellulose (C), after incorporation of CNCs (4\%) and different menthol oil contents 0.35 (D), $0.4(\mathrm{E}), 0.6(\mathrm{~F})$ and $0.8(\mathrm{G})$

The chemical structure of the chitosan/hydroxypropyl methylcellulose film and that of the blends obtained after incorporation of
CNCs and oil were also investigated using FTIR spectroscopy, as shown in Figure 3. 
SALAH A. A. MOHAMED et al.

The O-H stretching band can be observed at $3428 \mathrm{~cm}^{-1}$ and the $\mathrm{C}-\mathrm{H}$ stretching vibration mode band emerged at $2924 \mathrm{~cm}^{-1}$. 34 Also, the peak located at $1638 \mathrm{~cm}^{-1}$ corresponds to the presence of water molecules adsorbed onto the polymer surface. However, the intensity of these peaks decreased after adding menthol oil. The decrease in the band intensity at $3428 \mathrm{~cm}^{-1}$ could be attributed to the presence of CNCs, which decrease the intensity of hydroxyl groups.

\section{Mechanical properties}

Tensile strength properties: the tensile strength $(\mathrm{N} / \mathrm{m})$, Young's modulus, and percentage strain at maximum load for the chitosan/HPMC film with/without reinforcement with $\mathrm{CNCs}$ are shown in Figure 4 and Table 3. The obtained results indicate that the tensile strength of the chitosan/HPMC film is $100 \mathrm{~N} / \mathrm{m}$. The tensile strength $(\mathrm{N} / \mathrm{m})$ of the films reinforced with $\mathrm{CNCs}$ increased with a rising $\mathrm{CNC} \%$ in the composite films, leading to values by about $33 \%$ higher than that of the chitosan/HPMC film at $4 \% \mathrm{CNC}$ addition. This is due to the compact coating construction that fills the cracks and produces a firm, flat and smooth surface, enhancing the tensile strength of the films compared to the reference (Fig. 4).

The elastic modulus values indicate that increasing the $\mathrm{CNC}$ loading in the chitosan/HPMC films resulted in an increment in elastic modulus $(\mathrm{N} / \mathrm{m})$, which ranged from 56 to $203 \%$ with CNC loading from 1 to $4 \%$ (Fig. 4).

Table 3

Effect of different $\mathrm{CNC}$ ratios on the mechanical and physical properties of HPMC/chitosan composite films (at $30 \%$ constant ratio of glycerol)

\begin{tabular}{|c|c|c|c|c|c|}
\hline \multicolumn{3}{|c|}{ Reactants } & \multirow{2}{*}{$\begin{array}{c}\text { Swelling, } \\
\%\end{array}$} & \multirow{2}{*}{$\begin{array}{c}\text { Air } \\
\text { permeability, } \\
\mathrm{S}\end{array}$} & \multirow{2}{*}{$\begin{array}{c}\text { Percentage } \\
\text { strain at } \\
\text { maximum load }\end{array}$} \\
\hline $\begin{array}{c}\text { HPMC, } \\
\mathrm{g}\end{array}$ & $\begin{array}{c}\text { Chitosan, } \\
\mathrm{g}\end{array}$ & $\begin{array}{c}\mathrm{CNCs}, \\
\%\end{array}$ & & & \\
\hline 30 & 30 & --- & $21.99 \pm 1.48$ & Nil & $97 \pm 16.38$ \\
\hline 30 & 30 & 1 & $9.09 \pm 0.55$ & Nil & $102 \pm 16.90$ \\
\hline 30 & 30 & 2 & $9.14 \pm 0.03$ & Nil & $111 \pm 7.70$ \\
\hline 30 & 30 & 3 & $9.41 \pm 0.31$ & Nil & $63 \pm 10.57$ \\
\hline 30 & 30 & 4 & $10.79 \pm 0.60$ & Nil & $67 \pm 3.55$ \\
\hline
\end{tabular}

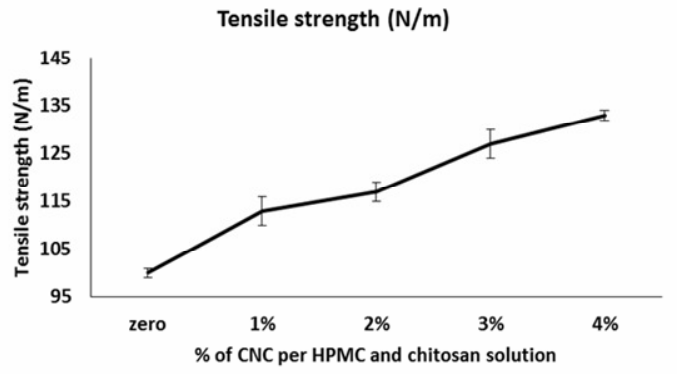

A)

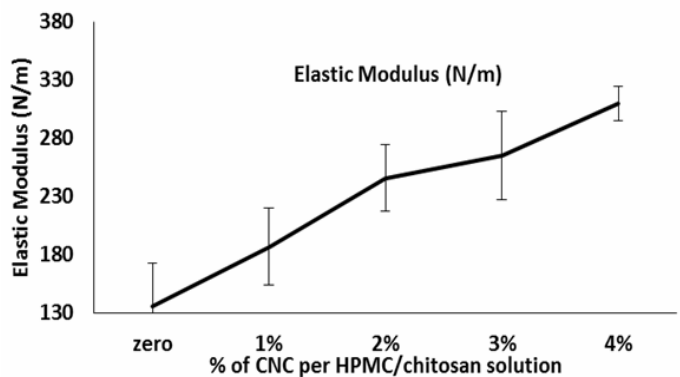

B)

Figure 4: Effect of CNC addition on: A) tensile strength. and B) elastic modulus of composite films

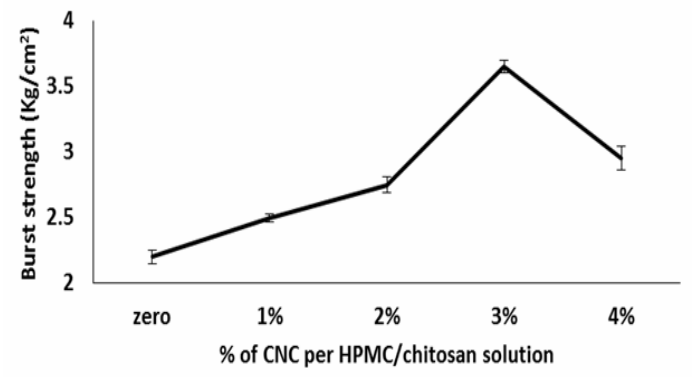

Figure 5: Effect of CNC addition on burst strength $\left(\mathrm{Kg} / \mathrm{cm}^{2}\right)$ of composite films 
Percentage strain at maximum load also rose with a higher $\mathrm{CNC}$ amount in the chitosan/HPMC film - it improved significantly upon adding $2 \% \mathrm{CNCs}$ into the solution, which is about $13 \%$ higher than that of the chitosan/HPMC film (Table 3).

The burst strength demonstrates the same behavior as tensile strength - the increase in the $\mathrm{CNCs}$ ratio (up to $3 \%$ addition) improves the burst strength of the films, as shown in Figure 5. The enhancement in the strength properties indicates that the negatively charged $\mathrm{CNCs}$ could serve as cross-linker within the positively charged chitosan/HPMC composite films via electrostatic attraction. The initial chitosan/HPMC film is more brittle and less flexible, compared with the plasticized one. Upon the addition of CNCs, the strength properties are improved, the CNCs acting as a cross-linker within the chitosan/HPMC films due to the attachment of the $\mathrm{OH}$ groups in CNCs to the amino groups in the side chains of chitosan, which also contributed to the results of air permeability, as will be discussed below. The addition of menthol oil did not affect much the mechanical properties.

\section{Water absorption behavior}

Water absorption was established by measuring the mass of different chitosan/hydroxypropyl methylcellulose films reinforced with cellulose nanocrystals (CNCs), before and after soaking in water (Table 3 ). The weight gain $\%$ was found to reach $22 \%$ for the chitosan/hydroxypropyl methylcellulose films, while it was $9-11 \%$ for the films reinforced with different amounts of CNCs (1, 2, 3 and 4\%). Also, it recorded $70 \%$ for the pure chitosan membrane after two hours of soaking in water.

This means that the modification process using hydroxypropyl methylcellulose reduced the water absorption properties of the pure chitosan membrane (absorption of $70 \%$ water), which decreased to $22 \%$. It was important to diminish water absorption in the films. Furthermore, the addition of cellulose nanocrystals further reduced the water absorption of the composite film to 9$11 \%$ by weight, compared with $22 \%$ after modification by HPMC only. These results are similar to those reported for a chitosan:citric acid:glycerol (1:1:9) film, which absorbed about $14 \%$ water by weight in two hours. ${ }^{35}$ The authors established that the swelling properties of a pure chitosan membrane, which absorbed $70 \%$ water, were modified after the addition of water-soluble cellulose derivatives. ${ }^{35}$ The prepared composite films did not crumble when submerged in water for more than 12 hours.

\section{Air permeability}

The air permeability values of the chitosan/HPMC film and CNC reinforced chitosan/HPMC films are tabulated in Table 3. The achieved results prove that the chitosan/HPMC films present no air permeability. Also, no air permeability was observed upon adding the surfactant into the coating solution. This is due to the fact that the compact coating structure fills the cracks, creating a flat, tight and smooth surface, with no air permeability.

\section{Effect of menthol oil on antimicrobial activity of composite films}

In the present study, the antimicrobial activity of chitosan modified films against E. coli (Gramnegative bacteria), B. mycoides (Gram-positive bacteria) and $C$. albicans (non-filamentous fungus) was studied. The antimicrobial activity was assessed by the agar diffusion method, from the growth of the inhibition zone width around the composite samples, in millimeters. The results of the films' antimicrobial activity are presented in Table 4. The data in Table 4 indicate that the treatments applied to the films had a strong biocide effect on $E$. coli, B. mycoides and $C$. albicans, which was confirmed by the wide zones of stunted microorganism growth, compared with the control samples. In this connection, the addition of menthol oil $(0.25 \mathrm{~mL})$ to the solution of HPMC and chitosan gave the maximum antibacterial activities against $E$. coli $(29 \mathrm{~mm})$ and B. mycoides $(28 \mathrm{~mm})$ respectively, expressed as the diameter of the growth inhibition zone. Meanwhile, menthol oil $(0.8 \mathrm{~mL})$ with $\mathrm{CNCs}$ (4\%) led to E. coli and B. mycoides growth inhibition zones of 28 and $27 \mathrm{~mm}$, respectively. Moreover, the addition of CNCs (4\%) without oil leads to an equal growth inhibition zone $(27 \mathrm{~mm})$ of both E. coli and B. mycoides. Optimum antinon-filamentous fungal activity against $C$. albicans $(24 \mathrm{~mm})$ was found in the case of employing menthol oil $(0.5 \mathrm{~mL})$ without $\mathrm{CNCs}$, and also when using CNCs (4\%) without menthol oil and Tween (Table 4).

The shake flask test method was also used for determining the antimicrobial activity of the 
SALAH A. A. MOHAMED et al.

antimicrobial agents under dynamic contact conditions in order to overcome the limitations of the classical test methods for the assessment of immobilized antimicrobials through direct contact of microorganisms with the active agent (Fig. 6). The results obtained were listed in Table 5, which indicates a complete colony forming unit (CFU) reduction $(100 \%)$ in the case of $E$. coli and $C$. albicans upon the addition of $4 \%$ of CNCs and $0.4 \mathrm{~mL}$ of menthol oil. The addition of CNCs
(4\%) with menthol oil $(0.35 \mathrm{~mL})$ to the solution of HPMC and chitosan causes a reduction percentage of 98.45 and $98.00 \%$ for $E$. coli and $C$. albicans, respectively. On the other hand, the highest microbial reduction against $B$. mycoides (95.89\%) was recorded for the addition of CNCs (4\%) and $0.35 \mathrm{~mL}$ of menthol oil to the solution. Furthermore, adding CNCs (4\%) with menthol oil $(0.8 \mathrm{~mL})$ to the solution of HPMC and chitosan led to a $94.64 \%$ reduction in B. mycoides CFU.<smiles>CC(C)[C@H]1CC[C@@H](C)C[C@H]1O</smiles>

Scheme 1: Chemical structure of menthol ${ }^{36}$

Table 4

Assessment of antibacterial activity of the films using the agar diffusion method

\begin{tabular}{ccccccccc}
\hline \multirow{2}{*}{$\begin{array}{c}\text { Sample } \\
\text { No. }\end{array}$} & $\begin{array}{c}\text { Chitosan, } \\
\mathrm{g}\end{array}$ & $\begin{array}{c}\text { HPMC, } \\
\mathrm{g}\end{array}$ & $\mathrm{CNC}$ & $\begin{array}{c}\text { Oil, } \\
\mathrm{mL}\end{array}$ & $\begin{array}{c}\text { Tween, } \\
\mathrm{mL}\end{array}$ & E. coli & B. mycoides & C. albicans \\
\hline 1 & 60 & --- & --- & --- & --- & $12 \pm 1.00$ & $12 \pm 0.50$ & $12 \pm 0.25$ \\
2 & --- & 60 & --- & --- & --- & $0 \pm 0.00$ & $0 \pm 0.00$ & $0 \pm 0.00$ \\
3 & 30 & 30 & --- & --- & --- & $24 \pm 2.00$ & $20 \pm 1.50$ & $23 \pm 0.50$ \\
8 & 30 & 30 & --- & 0.25 & 0.25 & $29 \pm 0.50$ & $28 \pm 0.19$ & $22 \pm 0.00$ \\
9 & 30 & 30 & --- & 0.5 & 0.5 & $22 \pm 0.10$ & $23 \pm 1.20$ & $24 \pm 0.00$ \\
10 & 30 & 30 & $4 \%$ & 0.35 & 0.35 & $11 \pm 1.50$ & $14 \pm 2.00$ & $14 \pm 0.10$ \\
11 & 30 & 30 & $4 \%$ & 0.4 & 0.4 & $21 \pm 0.33$ & $19 \pm 1.50$ & $21 \pm 0.15$ \\
12 & 30 & 30 & $4 \%$ & 0.6 & 0.6 & $22 \pm 0.00$ & $24 \pm 1.75$ & $22 \pm 0.45$ \\
13 & 30 & 30 & $4 \%$ & 0.8 & 0.8 & $28 \pm 1.33$ & $27 \pm 1.00$ & $22 \pm 0.66$ \\
\hline
\end{tabular}

*The diameter of the samples used was $12 \mathrm{~mm}$; chitosan and HPMC concentrations were maintained at $30 \mathrm{~g}$, whereas that of nanocellulose at $4 \%$, and of glycerol at $30 \%$

Table 5

Antimicrobial activity determination of the films under dynamic contact conditions

\begin{tabular}{ccccccccc}
\hline \multirow{2}{*}{$\begin{array}{c}\text { Sample } \\
\text { No. }\end{array}$} & $\begin{array}{c}\text { Chitosan, } \\
\mathrm{g}\end{array}$ & $\begin{array}{c}\text { HPMC, } \\
\mathrm{g}\end{array}$ & $\mathrm{CNC}$ & $\begin{array}{c}\text { Oil, } \\
\mathrm{mL}\end{array}$ & $\begin{array}{c}\text { Tween, } \\
\mathrm{mL}\end{array}$ & E. coli & B. mycoides & C. albicans \\
\hline Control & --- & --- & --- & --- & --- & 0.00 & 0.00 & 0.00 \\
HPMC & --- & 60 & --- & --- & --- & 0.00 & 0.00 & 0.00 \\
7 & 30 & 30 & $4 \%$ & -- & -- & $91.59 \pm 2.13$ & $92.14 \pm 1.45$ & $87.38 \pm 0.75$ \\
8 & 30 & 30 & ---- & 0.25 & 0.25 & $93.81 \pm 0.28$ & $88.93 \pm 3.06$ & $94.62 \pm 1.14$ \\
9 & 30 & 30 & ----- & 0.5 & 0.5 & $93.36 \pm 2.74$ & $90.54 \pm 1.03$ & $93.38 \pm 3.11$ \\
10 & 30 & 30 & $4 \%$ & 0.35 & 0.35 & $98.45 \pm 1.19$ & $95.89 \pm 0.93$ & $98.00 \pm 0.55$ \\
11 & 30 & 30 & $4 \%$ & 0.4 & 0.4 & $100.0 \pm 0.85$ & $93.75 \pm 1.54$ & $100.00 \pm 1.24$ \\
12 & 30 & 30 & $4 \%$ & 0.6 & 0.6 & $90.27 \pm 2.52$ & $90.36 \pm 0.83$ & $93.54 \pm 0.42$ \\
13 & 30 & 30 & $4 \%$ & 0.8 & 0.8 & $95.58 \pm 1.17$ & $94.64 \pm 0.63$ & $92.62 \pm 3.02$ \\
\hline
\end{tabular}

CFU: colony forming unit 


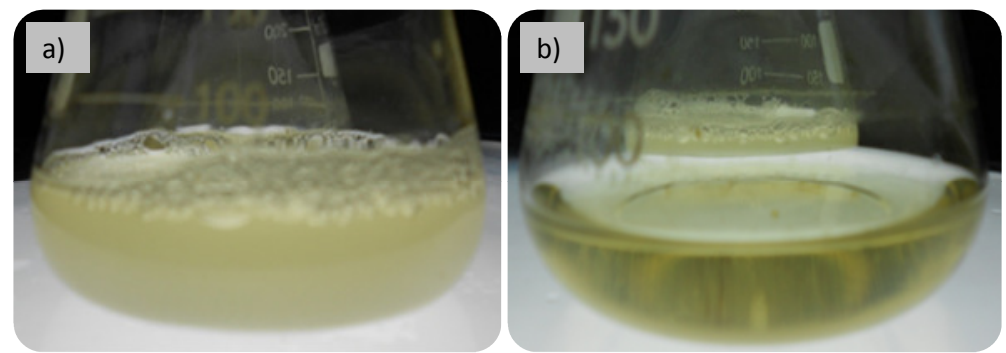

Figure 6: Antimicrobial activity determination of the films under dynamic contact conditions; the control sample (a) showed huge microbial growth, represented as dense turbidity, whereas the treated sample (b) has clear broth medium due to the absence of microbial growth as a result of the treatment process

Hernández-Muñoz et al. ${ }^{37}$ stated that chitosan has inherent antimicrobial activity towards Gramnegative and Gram-positive bacteria. However, usually, a neat film of chitosan has insufficient antimicrobial activity, which makes it unsuitable to prevent contamination with pathogenic bacteria. ${ }^{38}$ This was also demonstrated in the present study. Therefore, the inclusion of additional antimicrobial agents, such as HPMC and menthol oil, into the chitosan film undoubtedly enhanced the antimicrobial activity, according to the characteristics of the incorporated agents and the tested microorganisms, to inhibit the growth of pathogenic bacteria. ${ }^{39}$

\section{CONCLUSION}

The current study demonstrated the possibility to prepare modified chitosan films, with enhanced water resistance, biodegradability, antimicrobial activity, high mechanical properties and no oxygen permeability, entirely from renewable and non-toxic feedstock. Chitosan/hydroxypropyl methylcellulose films, reinforced with CNCs and containing menthol oil, were prepared through a simple and versatile solution mixing and casting method. The modification process using HPMC and $\mathrm{HPMC} / \mathrm{CNC}$ reduced the water absorption of the pure chitosan membrane from $70 \%$ to $22 \%$, and to $9-11 \%$ by weight, respectively. Thus, $\mathrm{HPMC} / \mathrm{CNC}$ reduced the water absorption of the composite film even more than HPMC alone. The prepared composite films showed homogenous morphology, high mechanical properties, and enhanced antibacterial activity. The current study proved that the addition of CNCs improved the mechanical properties of the produced films. In general, CNC may act as a crosslinker between chitosan/HPMC film layers due to the probable reaction between the residual sulphate groups (produced during the treatment of cellulose with sulphuric acids) and the amino groups in chitosan. The CNCs prepared by the acid degradation process contain a percent of sulphate, as revealed by the CNC spectra (sharp band at $1085 \mathrm{~cm}^{-1}$ ). All these factors contributed to the nil air permeability in the composite films. Also, the addition of CNCs, HPMC and menthol oil to the chitosan film undoubtedly improved the antimicrobial activity, based on the characteristics of these incorporated agents and of the tested microorganisms. Thus, such films can be used to prevent contamination resulting from pathogenic bacteria. Further research and development of polysaccharides-based films will encourage the use of presently underutilized, environmentally friendly starting materials as coatings and in packaging applications, where increased waterresistance is desirable.

ACKNOWLEDGMENT: The authors would like to express their gratitude to the National Research Centre, Egypt. The authors are also appreciative of the Director of the National Research Centre and of all cooperative employers.

\section{REFERENCES}

1 J. Sundaram, J. Pant, M. J. Goudie, S. Mani and H. Handa, J. Agric. Food Chem., 64, 5260 (2016), https://doi.org/10.1021/acs.jafc.6b01936

2 S. A. A. Mohamed, M. El-Sakhawy and M. A.-M. El-Sakhawy, Carbohyd. Polym., 238, 116178 (2020), https://doi.org/10.1016/j.carbpol.2020.116178

3 A. Salama, Environ. Nanotechnol., Monit. Manag., 8, $228 \quad$ (2017),

https://doi.org/10.1016/j.enmm.2017.08.003

${ }^{4}$ G. A. Olatunji, A. T. Kola-Mustapha, O. D. Saliu, A. B. Alabi, O. I. Abiodun et al., Korean J. Chem. Eng., 35, 784 (2018), https://doi.org/10.1007/s11814017-0314-8

5 W. Shao, X. Liu, H. Min, G. Dong, Q. Feng et al., ACS Appl. Mater. Interfaces, 7, 6966 (2015), 
https://doi.org/10.1021/acsami.5b00937

6 A. Salama and M. El-Sakhawy, Int. J. Biol. Macromol., $\quad$ 92, $\quad 920 \quad$ (2016), https://doi.org/10.1016/j.ijbiomac.2016.07.077

A. Salama, S. Etri, S. A. A. Mohamed and M. ElSakhawy, Carbohyd. Polym., 189138 (2018), https://doi.org/10.1016/j.carbpol.2018.02.016

8 M. S. Islam, L. Chen, J. Sisler and K. C. Tam, J. Mater. Chem. B. 6, $864 \quad$ (2018), https://doi.org/10.1039/c7tb03016a

9 J. Yang, C.-R. Han, X.-M. Zhang, F. Xu and R.-C. Sun, Macromolecules, 47, 4077 (2014), https://doi.org/10.1021/ma500729q

10 Y. Habibi, L. A. Lucia and O. J. Rojas, Chem. Rev., 110, 3479 (2010), https://doi.org/10.1021/cr900339w

11 A. Salama and P. Hesemann, Int. J. Biol. Macromol., $\quad 147, \quad 276 \quad$ (2020), https://doi.org/10.1016/j.ijbiomac.2020.01.046

12 C. K. S. Pillai, W. Paul and C. P. Sharma, Prog. Polym. Sci., 34, $641 \quad$ (2009), https://doi.org/10.1016/j.progpolymsci.2009.04.001

13 P. C. Srinivasa, M. N. Ramesh, K. R. Kumar and R. N. Tharanathan, J. Food Eng., 63, 79 (2004), https://doi.org/10.1016/S0260-8774(03)00285-1

14 A. Salama and M. El-Sakhawy, Carbohyd. Polym., 113, 500

(2014),

https://doi.org/10.1016/j.carbpol.2014.07.022

15 S. P. Noel, H. S. Courtney, J. D. Bumgardner and W. O. Haggard, Clin. Orthop. Relat. Res., 468, 2074 (2010), https://doi.org/10.1007/s11999-010-1324-6

16 M. Mucha and A. Pawlak, Thermochim. Acta, 427, 69 (2005), https://doi.org/10.1016/j.tca.2004.08.014

17 A. Pawlak and M. Mucha, Thermochim. Acta, 396, $153 \quad$ (2003), https://doi.org/10.1016/S00406031(02)00523-3

18 K. Sakurai, Polymer (Guildf), 41, 7051 (2000), https://doi.org/10.1016/S0032-3861(00)00067-7

19 Y. X. Xu, K. M. Kim, M. A. Hanna and D. Nag, Ind. Crop. Prod., 21, 185 (2005), https://doi.org/10.1016/j.indcrop.2004.03.002

20 Y. B. Wu, S. H. Yu, F. L. Mi, C. W. Wu, S. S. Shyu et al., Carbohyd. Polym., 57, 435 (2004), https://doi.org/10.1016/j.carbpol.2004.05.013

21 N. Sarkar and L. C. Walker, Carbohyd. Polym., 27, $177 \quad$ (1995), https://doi.org/10.1016/01448617(95)00061-B

22 C. Wollenweber, A. V. Makievski, R. Miller and R. Daniels, Colloid. Surfaces A, Physicochem. Eng. Asp., 172, 91 (2000), https://doi.org/10.1016/S09277757(00)00569-0

23 S. R. Illiger, C. Fadnis, T. Demappa, J. Jayaraju and J. Keshavayya, Carbohyd. Polym., 75, 484 (2009), https://doi.org/10.1016/j.carbpol.2008.08.014

24 S. A. A. Mohamed, M. El-Sakhawy, E.-S. H. A. Nashy and A. M. Othman, Int. J. Biol. Macromol., 136, 774 (2019), https://doi.org/10.1016/j.ijbiomac.2019.06.130

${ }^{25}$ I. Arvanitoyannis, I. Kolokuris, A. Nakayama, N. Yamamoto and S. Aiba, Carbohyd. Polym., 34, 9
(1997), https://doi.org/10.1016/S0144-8617(97)00089-

26 H. S. Blair, J. Guthrie, T. K. Law and P. Turkington, J. Appl. Polym. Sci. 33, 641 (1987), https://doi.org/10.1002/app.1987.070330226

27 J.-G. Gwon, H.-J. Cho, S.-J. Chun, S. Lee, Q. Wu et al., RSC Adv., 6, $9438 \quad$ (2016), https://doi.org/10.1039/C5RA26337A

28 A. M. El Nahrawy, A. B. A. Hammad, A. M. Youssef, A. M. Mansour and A. M. Othman, Appl. Phys. A, 125, $46 \quad$ (2019), https://doi.org/10.1007/s00339-018-2351-5

29 A. M. Abouelnaga, T. M. Meaz, A. M. Othman, R. A. Ghazy and A. M. El Nahrawy, Silicon, (2020), https://doi.org/10.1007/s12633-020-00448-8

30 H. Haase, L. Jordan, L. Keitel, C. Keil and B. Mahltig, PLoS One, 12, e0188304 (2017), https://doi.org/10.1371/journal.pone.0188304

31 N. Johar, I. Ahmad and A. Dufresne, Ind. Crop. Prod., $\quad 37, \quad 93 \quad$ (2012), https://doi.org/10.1016/j.indcrop.2011.12.016

32 G. Siqueira, J. Bras and A. Dufresne, Polymers $\begin{array}{llll}\text { (Basel), 2, } & 728 & \text { (2010), }\end{array}$ https://doi.org/10.3390/polym2040728

33 M. L. Hassan, R. E. A. Zeid, S. M. Fadel, M. El Sakhawy and R. Khiari, Int. J. Nanoparticles, 7, 261 (2014), https://doi.org/10.1504/IJNP.2014.067613

34 A. Salama, J. Colloid Interface Sci., 487, 348 (2017), https://doi.org/10.1016/j.jcis.2016.10.034

35 Z. Cui, E. S. Beach and P. T. Anastas, Green Chem. Lett. Rev., 4, 35 (2011), https://doi.org/10.1080/17518253.2010.500621

36 P. V. Dicpinigaitis, A. H. Morice, S. S. Birring, L. McGarvey and J. A. Smith, Pharmacol. Rev., 66, 468 (2014), https://doi.org/10.1124/pr.111.005116

37 P. Hernández-Muñoz, E. Almenar, V. Del Valle, D. Velez and R. Gavara, Food Chem., 110, 428 (2008), https://doi.org/10.1016/j.foodchem.2008.02.020

38 L. F. Zemljič, T. Tkavc, A. Vesel and O. Šauperl, Appl. Surf. Sci., 265, 697 (2013), https://doi.org/10.1016/j.apsusc.2012.11.086

39 S. Shankar and J.-W. Rhim, Food Hydrocoll., 82, 116

(2018), 